\title{
Forum
}

\section{Landfall and Coastal Lighthouses: The Future for Fixed Visual Aids}

\author{
C. H. M. Colchester
}

1. BACKGROUND. In the present circumstances, with the imminent introduction of full GPS coverage and the ready availability of radionavigation systems, at least in the developed world, and also considering the continual improvement of shipborne radar, this subject may be thought somewhat irrelevant. However, it is precisely for this reason and due to the fact that a large number of coastal visual aids are operating worldwide, that it is necessary to decide whether they should continue in operation, be modified, or even be further developed.

At the recent IALA conference in Holland (16-30 June 1990), there were many papers presented on the subject of buoys and minor lights and there was generally more emphasis on minor visual aids, which is to be expected since they mark port approaches and close coastal waters where radionavigation aids are less useful. Surprisingly, there were also several papers on helicopter operation, radio remote monitoring and diesel power supplies, which can only refer to major aids. No real discussion was forthcoming, however, on the actual requirement for major visual aids (intensity more than 100000 candelas) except for a paper from the UK authorities, who saw 'a continuing but diminishing need'.

There remains considerable indecision on the need to provide major visual aids in situations where positions can readily be obtained by radar or radionavigation systems. In fact, for this reason some coastlines in developing countries now remain unlit, whereas some time ago, coastal lights would have been deemed essential.

2. HISTORY. The major coastal lighthouse developed during the last century as basically the only aid to navigation available at night. It was not until the early twentieth century, when Gustav Dalen invented the gas flasher, that reliable and effective buoy and minor lights became available. Many major coastal and rock lighthouses were built to cover dangerous coasts. These lighthouses were expensive to build and, since they had to be manned, they were also expensive to operate and maintain. During the last decade much effort has been made to reduce this cost with de-manning, service by helicopter and the installation of remote monitoring and control. These are all fairly expensive options in themselves, which still leaves these large lighthouses as major cost items.

3. UTILITY ANDAVAILABILITY. In order to determine the utility of a light, it is of interest to compare the visual ranges for lights of various intensity against the ambient visibility, as in Table $\mathbf{I}$.

Ten-mile ambient visibility, with atmospheric transmission factor, $T=0^{\circ} 74$, is usually accepted as defining nominal range conditions and provides a satisfactory definition of the service area of a light. Twenty-mile ambient visibility, $T=0.85$, is sometimes quoted, but such ideal conditions occur too rarely, even in the tropics, to be useful for this purpose.

The table shows a roughly equal percentage loss of range with reducing intensity in 
TABLE I. LIGHT INTENSITY/VISIBILITY, GIVING EXPECTED RANGES FOR FIRST SIGHTING OF LIGHTS

\begin{tabular}{rcccc}
\hline & \multicolumn{3}{c}{ Ambient visibility (n. m.) } \\
\cline { 2 - 5 } Intensity & (candelas) & 10 & 5 & 2 \\
\hline 1000000 & 25.7 & 14.7 & 6.9 \\
100000 & 19.8 & 11.6 & 5.7 \\
50000 & 18.1 & 10.8 & 5.3 \\
20000 & 15.9 & 9.5 & 4.8 \\
5000 & 12.7 & 8.0 & 4.1 \\
1000 & 9.4 & 6.2 & 3.3 \\
\hline
\end{tabular}

all conditions, but it chiefly demonstrates the very poor availability of powerful lights in adverse conditions, given their service area. This fact is well known to anyone who has had to make a landfall in these conditions without radar. It also demonstrates that, although a major aid provides a significant increase in nominal range, the benefit in poorer visibility conditions, when the lights are really needed, is much less.

In the past there was no choice but to mark dangerous coasts with major aids on the coastline, but this is now not necessarily correct.

4. RECENT DEVELOPMENTS. The development of solar energy systems has caused a revolution in the design of visual aids. It is now quite possible to support a 2000 candela light on a small single-pile beacon. There is no longer any need to construct large structures to carry gas cylinder and battery housings. The size of a light-beacon structure is now basically determined by the need to provide a day or radar mark.

Applying solar energy to larger lights, in association with modern light sources, it is possible over most of that part of the world's surface covered by the main shipping routes to achieve a light with an effective intensity of 50000 candelas without the necessity to erect vast solar arrays. This intensity level is also practical in other ways; it gives a nominal range of 18 miles, which only requires a $35 \mathrm{~m}$ elevation to provide the corresponding geographical range. Also, in 5 -mile visibility conditions the range is a useful 10.8 miles, whereas an increase to 1000000 candelas only gives an extra 4 miles.

If effective intensity is restricted to 50000 candelas, apart from the possibility of using solar energy, it also becomes possible to use much smaller lighthouse equipment, which then means that the installation of equivalent back-up equipment becomes practicable. This would give a large increase in reliability; for instance, assuming the standard equipment has 95 percent availability, which is the minimum required of an aid to navigation by IALA, then an identical back-up should provide 99.75 percent availability, equivalent to one day of downtime during a year. In fact, with the use of more compact equipment and proper attention to the MTBF times of the electronic components, practical absolute reliability should be achievable. This should mean that fewer and less regular inspections are necessary and make the need for remote monitoring debatable.

There is, therefore, a good case for the future marking of hazardous coastlines with relatively inexpensive solar-powered lighthouses and lightbeacons with maximum intensities of around 50000 candelas.

5. AVAILABLE EQUIPMENT. At present the quartz halogen lamp is an excellent light source for providing lights of this intensity from low-voltage supplies. Its colour performance is poor, but this is generally unimportant for other than minor lights. It provides a small bright source with greater efficiency than conventional lamps. Unfortunately, in present-day lighthouse equipment this source has been used to provide 
high intensities at the expense of beamwidth, causing very short flash lengths when used in a rotating lantern.

The question of short flash lengths is a matter that the author feels has not been properly addressed by IALA, although it is especially important in low-visibility conditions if effective use is to be made of a light. Short flashes are particularly unsatisfactory when accompanied by a long eclipse period. If the bearing of the light is not registered immediately it is lost.

Previously, for major lighthouses, the rule was that the minimum flash length for single flash characters should be $0.3 \mathrm{~s}$ and for group flash characters $0.2 \mathrm{~s}$. Then some research was done on the subject by the US Coastguard, who reported that short flashes were quite acceptable so long as the flashes were repeated frequently, ${ }^{1}$ like the xenon flash lights sometimes mounted on high chimneys, which make very good aids to navigation. Unfortunately, it is just as difficult with present-day low-voltage rotating lanterns to provide a suitable group flash, without using excessive energy, as it is to provide a reasonable flash length. The Coastguard failed to comment on suitable flash lengths for long single-flash characters. A number of studies have been undertaken on this subject, but a very comprehensive report produced by the Maritime Research Institute of the Netherlands in 1982 only states that more work needs to be done. ${ }^{2}$

In present-day lanterns, the light beam is formed either by a parabolic reflector behind the lamp or by a plastic lens panel placed in front of it. In the reflector lantern, the reflectors generally used have a diameter of $200 \mathrm{~mm}$, which accounts for the very narrow beam. If smaller reflectors were used, not only would a wider beam be produced, but the whole apparatus could be made smaller. Likewise, in the lens lantern the lens panels used have a focal length of $95 \mathrm{~mm}$, made necessary by the need to accommodate a carousel lamp changer within the lens cylinder, therefore use of a lens with a shorter focal length would involve some other means of lamp changing. In either case smaller equipment would appear to be necessary, and this would be in line with the requirement to provide more compact and easily-handled lanterns.

6. CONCLUSIONS. It is now quite possible for ships to navigate in many parts of the world using only electronic aids to navigation. However, it is never good policy to rely on only one system and, since there will always be a requirement for buoyage and minor lights, the lighthouse service must continue in operation. It would seem sensible to continue to provide large coastal lights, as long as these are provided on a rational basis without an undue allocation of resources.

Given suitable equipment, it should now be quite possible to mark landfalls and prominent coastal points and dangers with medium-sized light with an effective intensity of about 50000 candelas. These lights should be inexpensive and highly reliable if suitable redundancy is built into the system and if MTBF times are not exceeded on the electronic equipment. Maintenance should be minimal, involving no more than an annual visit, which could be carried out either by road and small boat, or by a buoy tender at a convenient time in its buoy maintenance schedule. Actual maintenance would ideally involve replacement of the lighting equipment for servicing in the workshop ashore, thereby saving buoy tender time.

There is no longer very much need for large and elaborate systems, which have been a feature of the past and, to some extent, the present. Much has been written recently on the subject of reducing the costs of providing aids to navigation. The general consensus would appear to be that this may be achieved by discontinuing light stations and reducing the services provided. The author believes that this is a mistaken policy since, by attempting to fulfil the actual requirement and by the proper application of modern technology, it should be possible to reduce costs to a level at which it would 
be unreasonable to reduce services and perhaps it would even become attractive to expand them.

\section{REFERENCES}

1 US Coastguard Ocean Engineering Report no. 37, p. 48. June 1970.

2 Drijhout van Hooff, J. F. (1982). Aids to Marine Navigation, p. II-48.

KEY WORDS

1. Lights and buoyage. 2. Safety.

\section{Navigation with $\mathrm{km}$ and gon}

\section{Sven Stubert}

I. INTR ODUCTION. Shipping and aviation have gone metric like society in general and charting is moving the same way except for the use of the nautical mile and the knot. In 1969 the Comite International des Poids et Mesures (CIPM) classified them for temporary use and only for purposes already common.

In 1974 it was recommended by IMCO, the predecessor of the International Maritime Organization (IMO), that the nautical mile and knot should be used in navigation until further notice. The International Civil Aviation Organization (ICAO) has also recommended its members to use the nautical mile and knot throughout - which was not always the case - for some time to come. A change of the present practice is now under consideration, especially by the following organizations :

- Subcommittee on Safety of Navigation, formed by the Maritime Safety Committee (MSC) under IMO in London,

- Replacement of the Nautical Mile Panel (RNMP), formed by the Air Navigation Commission under ICAO in Montreal.

IMO and ICAO are 'specialized agencies' within their parent organization, the United Nations.

As units for distance, speed, direction and position are closely connected in navigation, they will all be dealt with below. It will then be found that there are mainly the following two systems or combinations of units to choose between. (See also appendix 1.)

Mode A: nautical mile, knot, degree, minute (of arc).

Mode B: km, km/h, gon (grade), cgon (centigon).

2. REASONS FOR A CHANGE. Formerly, sailing and sea navigation were a very specialized business, separate from life on land. In those days, sailors could very well have their own units for ships, cargoes and navigation, but today life is different. There are no longer such barriers between sea, submarine, offshore, land, road and air activities. Now there are many more common interests and cooperation in transportation, because transport by sea, on land and in the air are only parts of overall transport systems, and the shipper who sends his goods desires only one business contract, 